\title{
Coletivo Geodésica Cultural Itinerante e a Revolução dos Baldinhos
}

Coletivo Geodésica Cultural Itinerante*

http://dx.doi.org/10.22409/poiesis.1829.015026

RESUMO: O projeto "Coletivo Geodésica Cultural Itinerante e a Revolução dos Baldinhos" foi uma proposta de arte pública colaborativa que ocorreu entre 2012 e 2013 no bairro Chico Mendes em Florianópolis, e que envolveu membros do Coletivo Geodésica Cultural Itinerante formado por estudantes, artistas e professores do CEART/UDESC, coordenado pelo Prof. Dr. José Luiz Kinceler (in memoriam), mulheres agentes do Projeto Revolução dos Baldinhos, alguns integrantes da ong CEPAGRO (Centro de Estudos e Promoção da Agricultura de Grupo), crianças e moradores locais.

PALAVRAS-CHAVE: Coletivo Geodésica Cultural, Revolução dos Baldinhos, arte pública colaborativa

ABSTRACT: The project "Itinerant Cultural Geodesic Collective and the Baldinhos Revolution" was a collaborative public art proposal that took place between 2012 and 2013 in the Chico Mendes neighborhood in Florianópolis, involving members of the Itinerant Cultural Geodesic Collective, formed by students, artists and professors of the CEART / UDESC, coordinated by Prof. Dr. José Luiz Kinceler (in memoriam), female agents of the Baldinhos Revolution Project, some members of CEPAGRO (Center for Studies and Promotion of Group Agriculture), children and local residents. KEYWORDS: Coletivo Geodésica Cultural, Revolução dos Baldinhos, collaborative public art

\footnotetext{
*Integrantes do Projeto Geodésica Cultural Itinerante 2012/2013: José Luiz Kinceler, João Calligaris Neto, Paulo Renato Damé, Tatiane da Rosa, Antonia Wallig, Leonardo Lima da Silva, Bruna Maresch, Helton Patricio Matias, Paulo Villalva, Lucas Sielski Kinceler, Gustavo Tirelli, Camila Argenta, Pedro Frieberg, Raphael Duarte Alves Augusto, Adson Loth, Aires de Souza, Paula Tonon Bittencourt, Vitor Ribeiro e Rafael Neckel Machado

Integrantes do Projeto Revolução dos Baldinhos / CEPAGRO: Cintia Cruz, Ana Karolina da Conceição, Rose Helena Rodrigues, Julio Maestri (CEPAGRO), Marcos José de Abreu (CEPAGRO)
}

Fotos: Lucas Sielski Kinceler (lucaskinceler@gmail.com), José Luiz Kinceler e Leonardo Lima. 
O projeto "Coletivo Geodésica Cultural Itinerante e a Revolução dos Baldinhos" foi uma proposta de arte pública colaborativa que ocorreu entre 2012 e 2013 no bairro Chico Mendes em Florianópolis, e que envolveu membros do Coletivo Geodésica Cultural Itinerante formado por estudantes, artistas e professores do CEART/UDESC, coordenado pelo Prof. Dr. José Luiz Kinceler (in memoriam), mulheres agentes do Projeto Revolução dos Baldinhos, alguns integrantes da ong CEPAGRO (Centro de Estudos e Promoção da Agricultura de Grupo), crianças e moradores locais.

A Revolução dos Baldinhos é um projeto de agricultura urbana que, em parceria com a CEPAGRO e moradores, transforma os resíduos orgânicos da comunidade em adubo desde 2008. Para complementar a proposta da "Revolução" de promover a agricultura urbana em sua própria comunidade, realizou-se uma parceria entre os dois grupos a partir da construção de hortas verticais com pneus reutilizados. As hortas verticais serviram como dispositivo relacional estimulando a troca de saberes para a materialização de desejos coletivos. Foram utilizadas táticas para ativar o processo criativo colaborativo baseadas no princípio da descontinuidade, experiência, convivência e afeto. Um processo criativo que envolveu o cruzamento entre referentes de outros campos de saber e proporcionou diversas ações, tais como cortejos de instalação das hortas, projeção de vídeo, oficinas de cerâmica, sementeiras em argila para produção de mudas, histórias em quadrinhos, criação de roteiro, graffiti e, posteriormente, o game "As aventuras de Zé Baldinho".

Tal proposta instaurou uma microecologia cultural na intersecção entre educação meio-ambiental, sustentabilidade e criatividade. A arte hoje, ao transbordar seus limites, se propõe a presentificação de modos de vida possíveis de se realizarem em colaboração com o público. É espaço-tempo vivenciado de uma maneira engajada, solidária e afetiva, pois participa da construção de imaginários coletivos que desejam transformar uma dada realidade imediata.

\section{Referências}

Links para outros materiais produzidos pelo Projeto Geodésica Cultural Itinerante: Horta, pneu \& baldinho - https://www.youtube.com/watch?v=F9WTDlu2ACQ

Cortejo - https://www.youtube.com/watch?v=wBXHhfdhNuc

Reino dos Ratos - https://www.youtube.com/watch?v=mcEV2yG5Jwg

Forno da Revolução - https://www.youtube.com/watch?v=9CUo6gdLtYY

Game produzido por Paulo Villalva - http://zebaldinho.blogspot.com.br/

Link para a Revolução dos Baldinhos no site da CEPAGRO:

https://cepagroagroecologia.wordpress.com/tag/revolucao-dos-baldinhos 


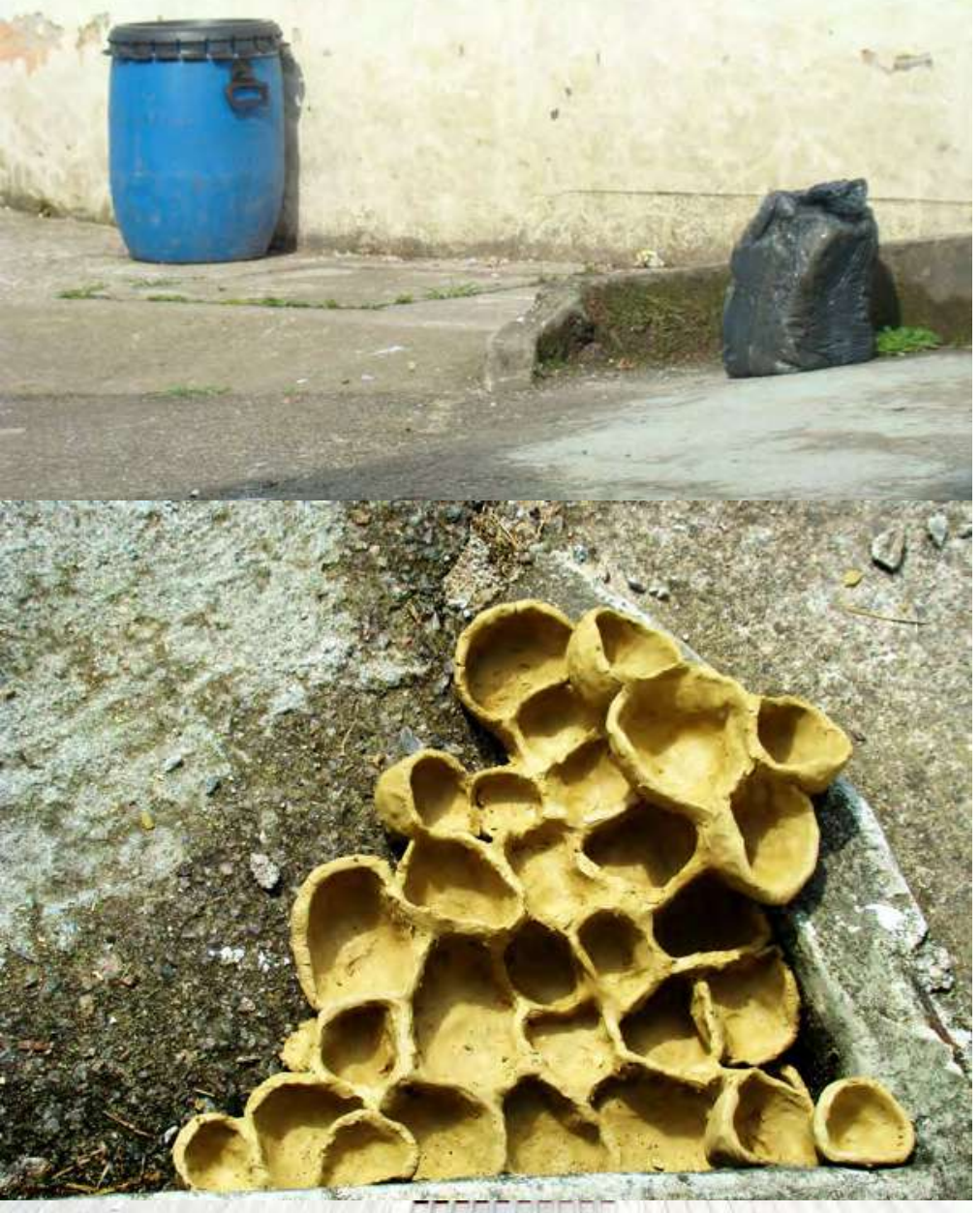

"A construção de hortas verticais por meio da reutilização de pneus automotivos descartados pelos consumidores serve, por sua vez, como um dispositivo relacional para a disseminação de outros saberes artísticos que a elas estão vinculadas. Foi o caso das sementeiras modeladas em argila, que propiciou a criação de uma oficina de iniciação à cerâmica e, por conseguinte, a confecção de vasos de parede cujo objetivo é gerar renda às mulheres."

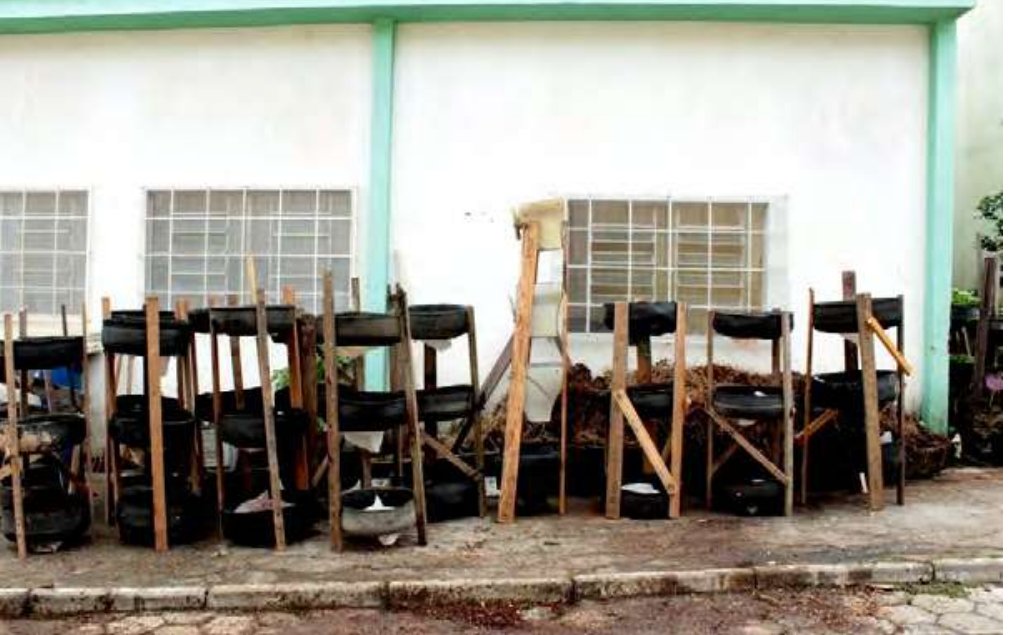




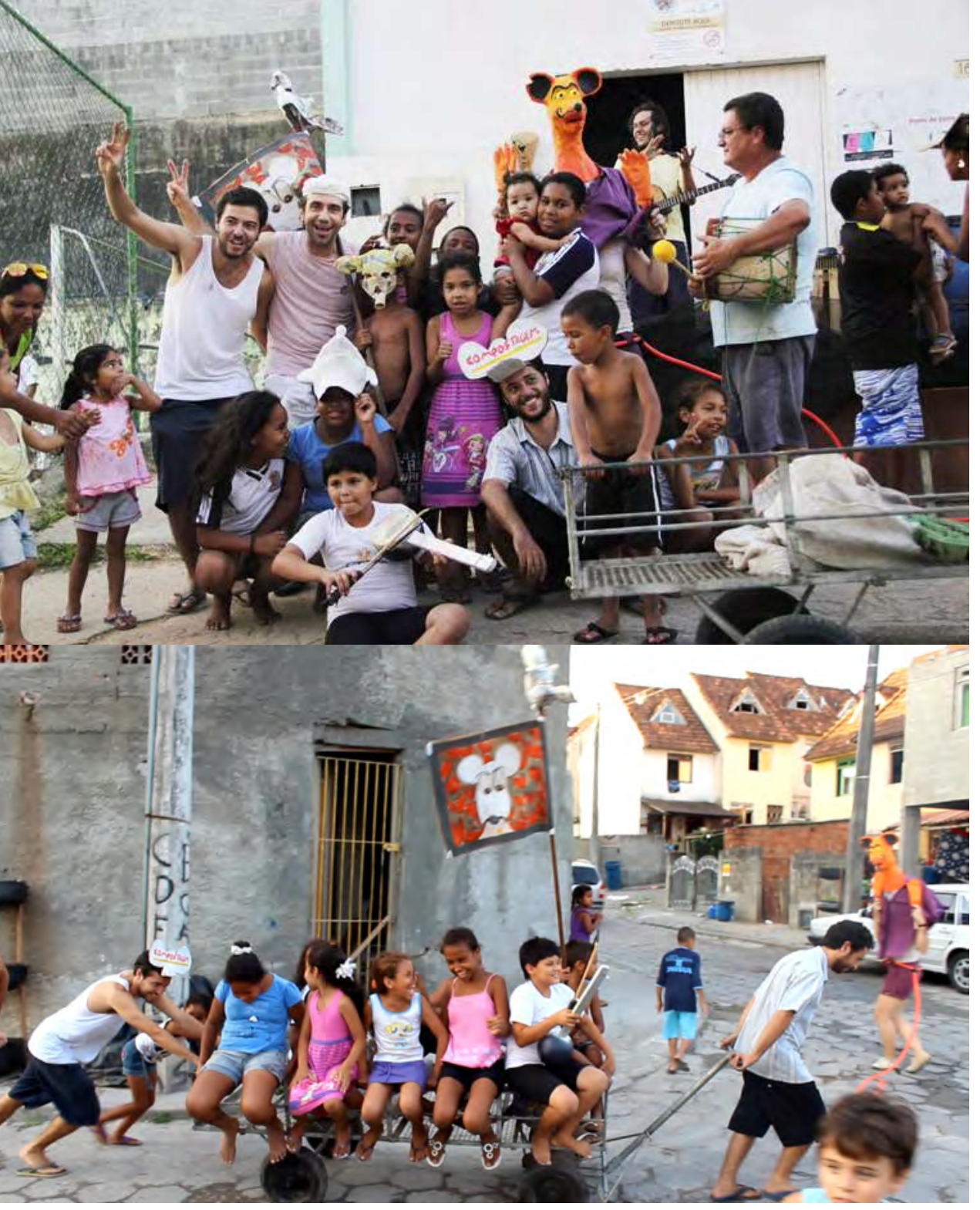

"Dentro da lógica de participação ativa e colaborativa à qual o público está sendo implicado, não deixa de nos surpreender que novas formas de praticar o jogo representacional da arte pública coloquem a criatividade dos participadores em beneficio do contexto social ao qual está vinculado." 
"Uma das formas de colaboração artística teve como proposta a disseminação do saber fazer hortas verticais com pneus reutilizados nos espaços públicos da comunidade. Para a efetivação desta proposta, o processo criativo compartilhado envolveu uma série de eventos nas ruas da comunidade e em frente à sede da Revolução, entre os quais: cortejos animados com os personagens 'ratos' de nosso roteiro que, de uma forma performática e improvisada e junto com as crianças da comunidade, conduziam animadamente os carrinhos da Revolução transportando as hortas verticais para serem instaladas nas ruas e calçadas da Comunidade Chico Mendes."

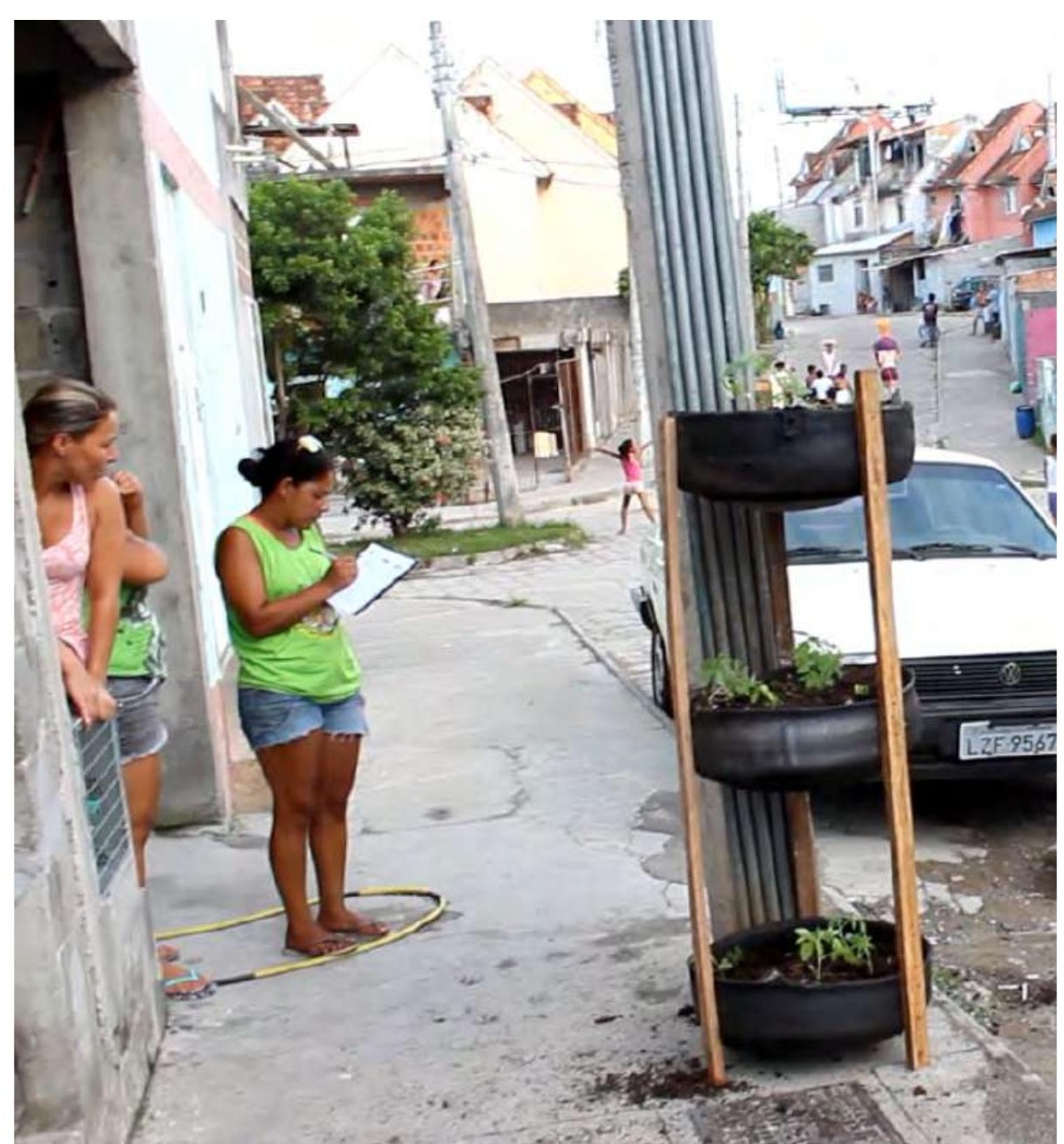


“(...) uma horta vertical não se realiza sem a presença de mudas que Ihe proporcionem o devido sentido; [portanto], a primeira descontinuidade do Coletivo foi realizar uma oficina de cerâmica para modelagem de sementeiras e vasos."

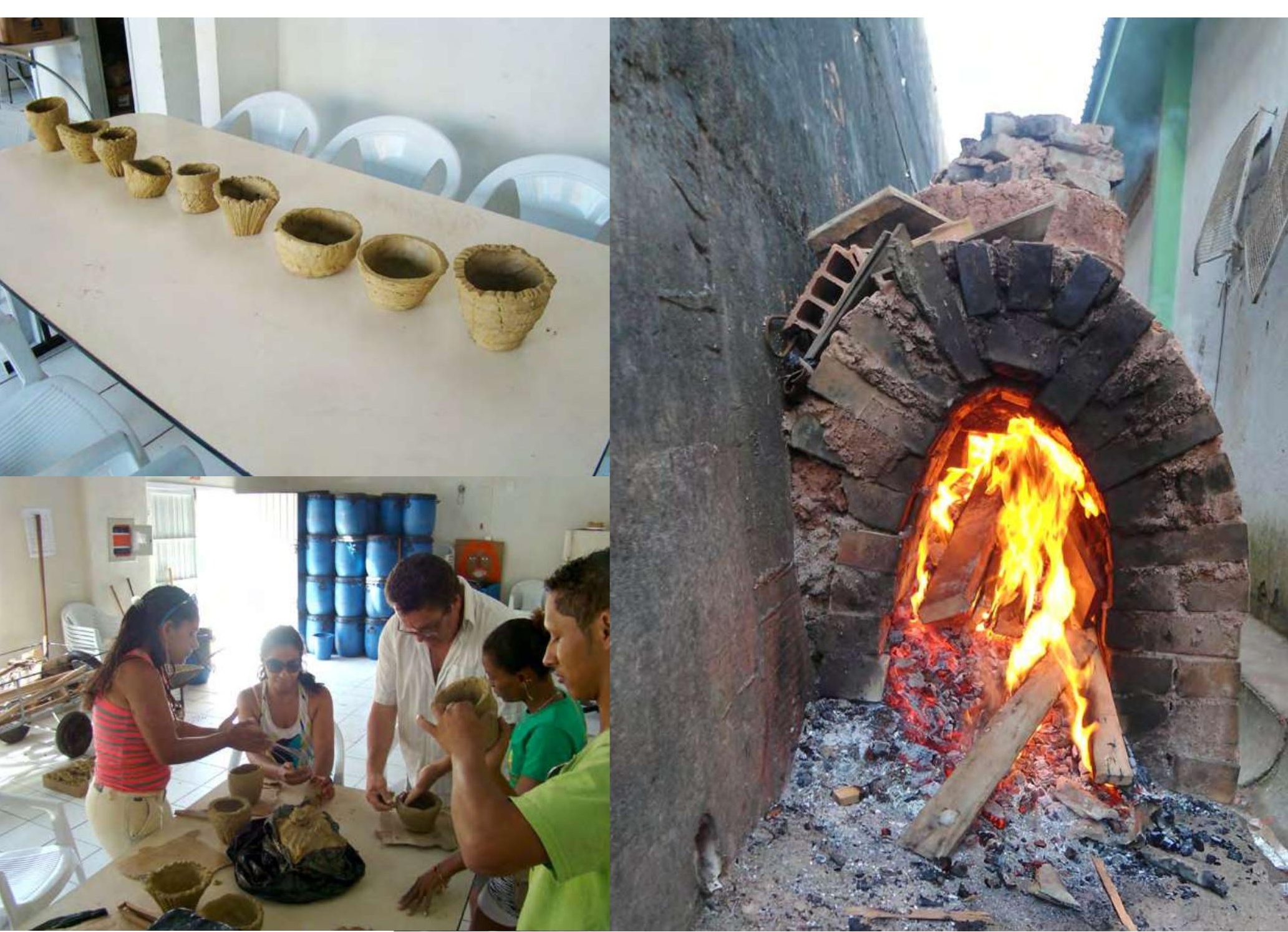




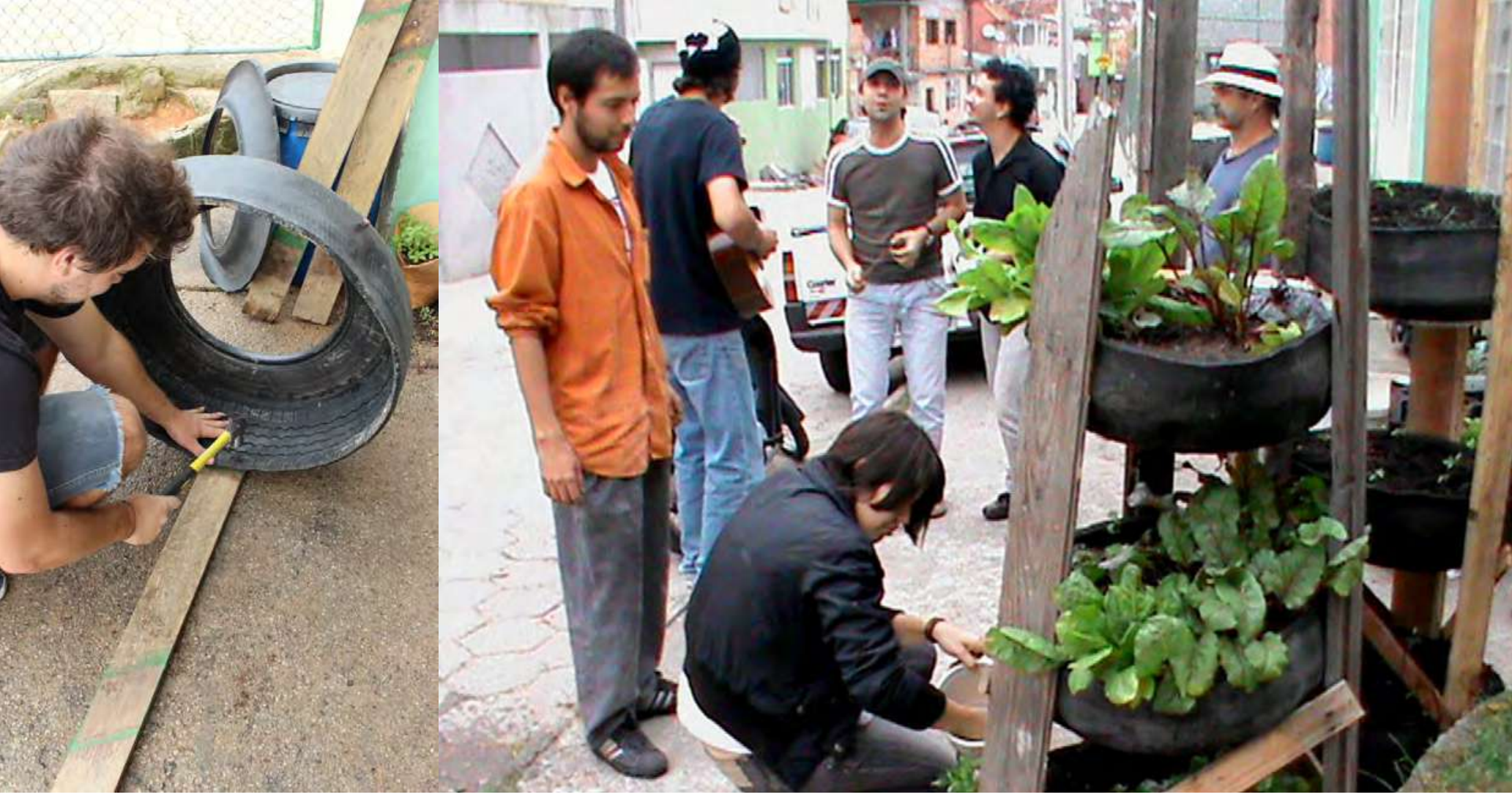

"Neste processo ficou evidente que com arte poderíamos preencher um interstício que efetivamente ainda se encontrava em potência de ser solucionado. Como promover representatividade do saber daquelas mulheres dentro da própria comunidade? Como fazer com que a própria comunidade sinta que o projeto Revolução dos Baldinhos Ihe pertence? Que tipo de imagens compartilhadas poderíamos extrair do real até então vivenciado de forma a promover visibilidade e empoderamento à própria comunidade da Chico Mendes?" 
"Ao estarmos dispostos a nos contaminar com os saberes da Revolução, a primeira tática criativa elaborada conjuntamente com as mulheres foi a de escrevermos um roteiro experimental contando de forma lúdica o processo da compostagem termofílica, tendo como argumento a história de alguns ratos que, ao entrarem nas leiras, se transformavam em bonecos animados conscientes de sua nova condição e em busca de sua história."

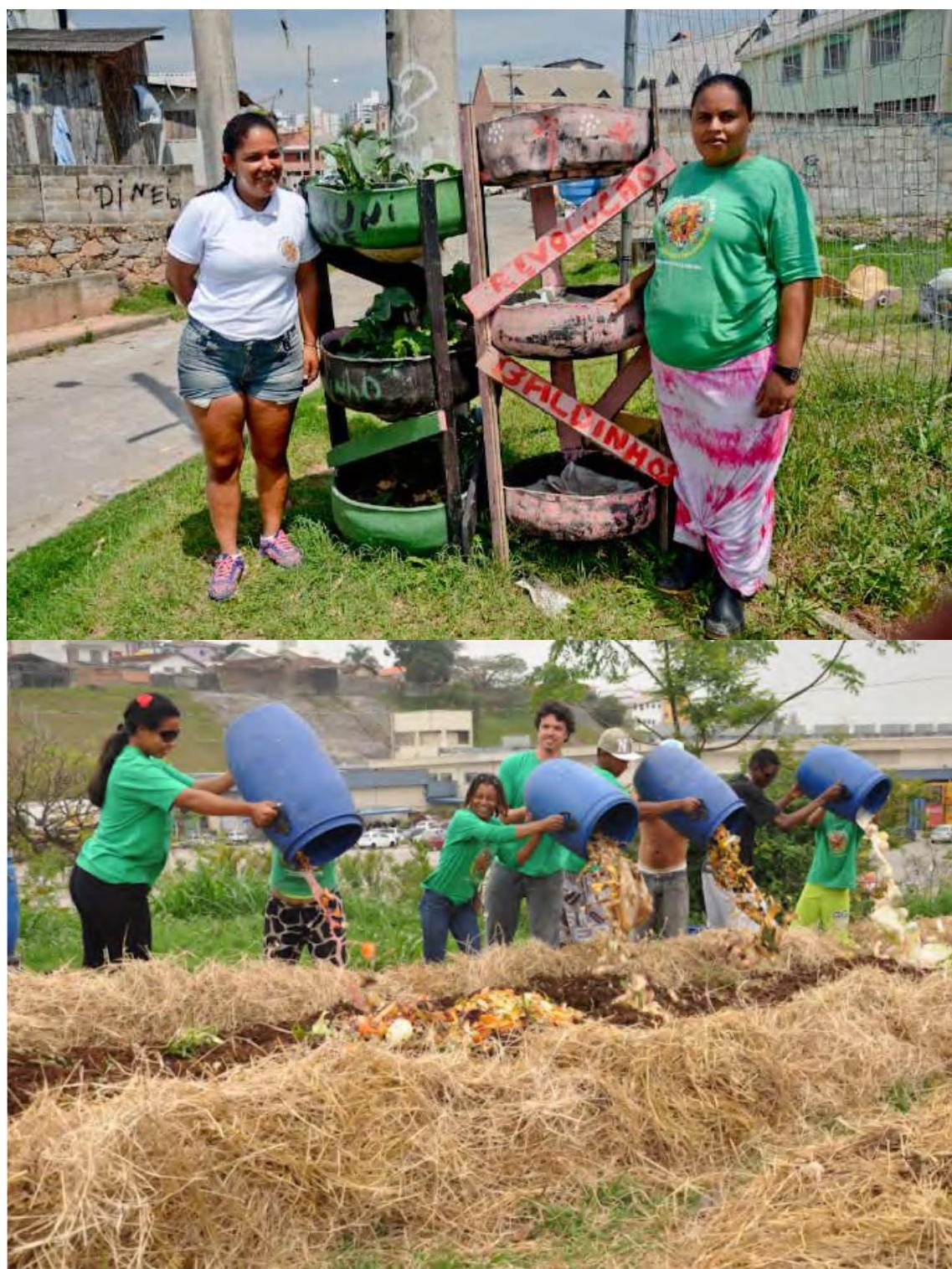




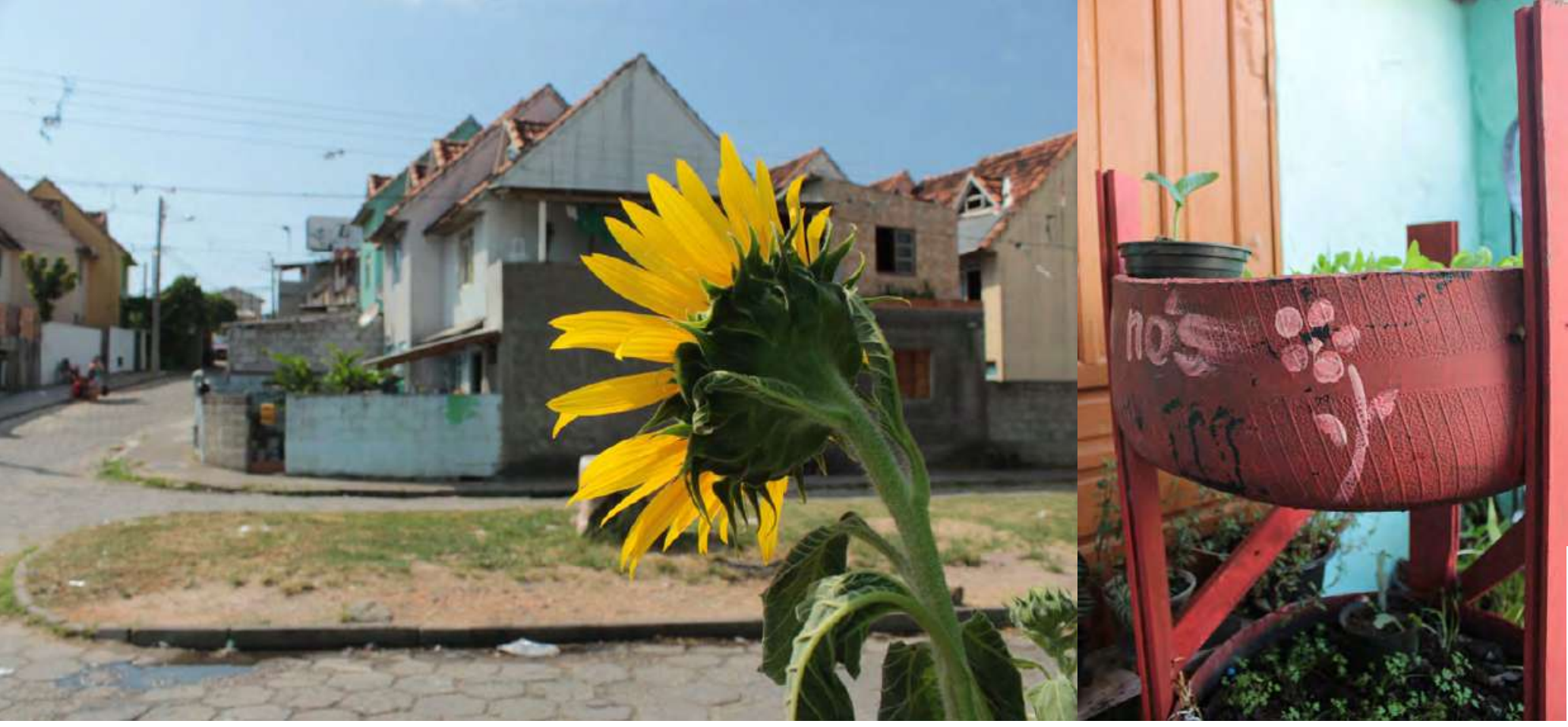

"A proposta artística implementada junto com as mulheres da Revolução dos Baldinhos passou a exigir deslocamentos processuais que transitaram entre lógicas de experimentar o cotidiano de forma complexa, que se reinventaram em função de descontinuidades potencializadoras de acontecimentos, além de estar dispostos a materializar o processo criativo de forma dialógica e, principalmente, praticar formas de existência complexas capazes de reinventar nossa subjetividade junto com o outro." 
